\title{
Pancreatic Lipase and Its Related Protein 2 Are Regulated by Dietary Polyunsaturated Fat during the Postnatal Development of Rats
}

\author{
RUTH Z. BIRK, KAREN S. REGAN, ELIZABETH BOYLE-RODEN, AND PATSY M. BRANNON \\ The Institute of Applied Biosciences, Department of Biotechnology Engineering [R.Z.B], Ben-Gurior \\ University, Beer-Sheva, 84105, Israel; and Department of Nutrition and Food Science [K.S.R., E.B.-R., \\ P.M.B.], University of Maryland, College Park, MD 20742, U.S.A.
}

\begin{abstract}
The developmental gene expression of pancreatic lipase (PL) and its related proteins (PLRP1 and PLRP2) is anticoordinate. It is unknown whether dietary fat regulates the expression of these proteins in the preweanling stage. For determining the regulation of development and diet on PL, PLRP1, and PLRP2 as early as the suckling period, pregnant (Sprague-Dawley) rats consumed from day 15 (d15) of pregnancy through $\mathrm{d} 9$ of lactation a purified low (11\% of energy) safflower oil diet [low-fat (LF)]. From d9 of lactation, dams and their respective pups were fed LF, mediumfat (MF; 40\% of energy), or high-fat (HF; 67\% of energy) safflower oil diets to d56. Milk fatty acid content had 15- to 100-fold less C:10 and 2.6- to 3.3-fold more C18:2 in MF and HF groups. Diet ( $\mathrm{LF}<\mathrm{MF}=\mathrm{HF} ; P<0.002$ ), postnatal development $(\mathrm{d} 15<\mathrm{d} 21<\mathrm{d} 28=\mathrm{d} 56 ; P<0.001)$, and interaction of diet $\times$ development significantly affected PL activity starting as early as d15. PL mRNA levels showed a parallel effect of diet $(\mathrm{LF}<\mathrm{HF}=\mathrm{MF} ; P<0.013)$ and development $(P<0.001)$. Both PLRP1 and PLRP2 mRNA levels were significantly af-
\end{abstract}

\section{ABSTRACT}

fected by development $(P<0.001)$ and had an anticoordinate pattern compared with PL expression $(\mathrm{d} 15>\mathrm{d} 21>\mathrm{d} 28)$. Reported for the first time is the significant down-regulation of PLRP2 mRNA levels by high polyunsaturated fat in suckling (d15) rats. In conclusion, PL and PLRP2 gene expression is regulated anticoordinately by the amount of dietary polyunsaturated fat starting as early as the preweanling phase of development. (Pediatr Res 56: 256-262, 2004)
FFA, free fatty acid
Abbreviations
HF, high fat
LF, low fat
MF, medium fat
PL, pancreatic lipase
PLRP2, pancreatic lipase-related protein 2
PLRP1, pancreatic lipase-related protein 1
PUFA, polyunsaturated fatty acids

Dietary fat provides the major energy $(\sim 50 \%$ calories $)$ during infancy in breast milk and formulas (1). During the past decade, special attention has been given to the type of fat necessary for normal infant development, especially to longchain polyunsaturated fatty acids (PUFA). PUFA derived from essential fatty acids (C18:2, linoleic acid, and $\mathrm{C} 18: 3 \alpha-$ linolenic) play a key role in brain and normal retinal development (2).

Fat digestion and absorption in the infant and premature neonate depend on the developmental pattern of lipases (3). The digestive system continues to develop after birth in infants, and especially so in premature neonates, influencing their ability to digest fat. Gastric lipase, which starts the digestion of

Received December 9, 2003; accepted March 15, 2004.

Correspondence: Ruth Birk, Ph.D., The Institute for Applied Biosciences, Department of Biotechnology Engineering., Ben-Gurion University. P.O. Box 653, Beer-Sheva 84105, Israel; e-mail: rbirk@bgumail.bgu.ac.il

DOI: 10.1203/01.PDR.0000132754.42306.B9 dietary fat and accounts for $10-30 \%$ of fat digestion (4), pancreatic colipase-dependent lipase, and milk bile saltstimulated lipase all have potential roles in digestion of milk fat in the neonate (3). Pancreatic lipase-related protein 2 (PLRP2) may play a role in neonatal fat digestion as well (5). Although the pancreatic lipase levels in the newborn and even more so in the premature infant are low, the digestion of milk fat depends on these four lipases with unique and only partially overlapping functions (5-7).

The exocrine pancreas synthesizes and secretes pancreatic lipase and two pancreatic lipase-related proteins; PLRP1 and PLRP2. PL and its related proteins have been identified in humans and rats. The PLRP1 is highly homologous to PL with conserved serine and histidine residues in the active site $(8,9)$; however, this protein does not exhibit colipasedependent lipolytic activity when its full-length cDNA is expressed in COS or Sf9 cells $(8,9)$. Although PLRP1 is secreted by the exocrine pancreas in several species (10), the function of PLRP1 remains unknown. Three reports 
(11-13) suggested that two mutations in residues 179 and 181 (alanine and proline to valine and alanine, respectively) render PLRP1 inactive. The second related protein (PLRP2) exhibits different lipolytic properties than PL. Even though PLRP2 has a limited activation by colipase in the presence of bile salts, PLRP2 has considerable lipolytic activity in the absence of colipase and has both phospholipase and galactolipase activities (14).

The postnatal developmental pattern of PL and its related proteins is anticoordinate in human and rat $(9,15)$. The mRNA levels of PLRP1 and PLRP2 are high in the suckling only phase (days 0-14), decrease in the suckling-nibbling phase (days 14-21), and are low throughout weaning and adulthood (21 d and later). In contrast, PL is not expressed at detectable levels until postnatal day 14 (d14), and its expression increases throughout the suckling-nibbling and weanling phases to maximal levels in adulthood. It has been proposed that the anticoordinate expression of PL and its related proteins may reflect different roles in lipid digestion during postnatal development (9). Supporting their proposal, Lowe et al. (5) found a decreased neonatal dietary fat absorption and digestion in PLRP2 knockout mice.

PL is the main enzyme responsible for digestion of dietary triglycerides in the weaned and adult period (4). In the presence of colipase and bile salts, PL hydrolyzes dietary triglycerides in the small intestine to two-monoglycerides and free fatty acids (FFAs) — which are then absorbed. Both humans and rats adapt the synthesis of pancreatic lipase in response to dietary variations and thereby maximize the utilization of dietary fat (16). The physiologic importance of this dietary regulation has been shown. The up-regulation of PL enhances the response of cholecystokinin to increased dietary fat by increasing the rate of digestion of triglycerides and the release of FFAs in the proximal small intestine (17). In weanling animals, PL and PLRP1 adapt to increased dietary fat (41-75\% of total energy) within $24 \mathrm{~h}$. After $5 \mathrm{~d}$, PL and PLRP1 reach higher steady-state levels of PL activity and synthesis and PL and PLRP1 mRNA (16-22).

The regulation of PL and PLRP1 by type of fat (chain length and degree of saturation) is controversial. We have previously shown that PL is regulated similarly by different types of fat above a threshold of $49 \%$ of energy as fat (21) and that highly polyunsaturated fat and fat rich in medium-chain triglycerides stimulate PL gene regulation below that threshold (20). It is unknown whether the gene expression of PL, PLRP1, and PLRP2 is modified by dietary fat in the suckling phase, when the pups consume only maternal milk, or in the sucklingnibbling phase of development, when the pups consume both maternal milk and maternal diet.

The fatty acid composition of maternal milk can be modified by altering the amount of polyunsaturated fat in the lactating dam's diet (23-25). The aim of this study was to determine whether the amount of polyunsaturated dietary fat can regulate PL, PLRP1, and PLRP2 during development including the suckling only, nibbling-suckling, weanling, and adult phases and to determine whether there is an interaction of this dietary regulation with the developmental regulation of $\mathrm{PL}$ and its related proteins when PUFA are introduced as early as the preweanling age.

\section{METHODS}

Experimental protocol. Fourteen-day timed pregnant female Sprague-Dawley rats (Charles River Lab, MA, U.S.A.) were housed individually in nursing cages in a temperaturecontrolled $\left(24^{\circ} \mathrm{C}\right)$ room with a $12: 12$-h light-dark cycle and were fed a nonpurified commercial diet for the first $24 \mathrm{~h}$. From the $\mathrm{d} 2$ until the $\mathrm{d} 9$ after delivery, dams were fed a low-fat (LF; $11 \%$ of energy as safflower oil) purified AIN-76 diet ad libitum (Table 1). For adjusting the rats to the milking procedure, pregnant rats were held routinely in milking position every day while the milking pump was on until delivery. From delivery until d9, dams and pups were disturbed only to feed and water them to reduce cannibalism. On d9, litter size was reduced to 11-13 without regard to sex of pup to standardize litter size and milk availability. On d9, lactating dams (with their respective pups) were randomly assigned to one of three diets: LF (11\% of energy as safflower oil), moderate fat (MF; 40\% of energy as safflower oil), or high fat (HF; 67\% of energy as safflower oil; Table 1). These diets were isoenergetic and isonitrogenous but varied in the content of cellulose (to maintain the same caloric density), which has been shown not to affect the regulation of the exocrine pancreas (26). On d21 after delivery, all progeny were weaned to the respective maternal diet for the duration of the study and were housed individually in hanging cages. The dams were milked at $\mathrm{d} 9$ and $\mathrm{d} 15$ after delivery. Before milking, dams received an intraperitoneal injection of oxytocin (1 U/100 g body weight). Milk was obtained in capillary tubes attached to a vacuum pump. Suction was regulated manually. Individual milk samples were stored at $-80^{\circ} \mathrm{C}$. The protocol was approved by the University of Maryland ACUC committee, and the NRC's guide for the care and use of laboratory animals was carried out.

Food consumption was measured daily. Pup body weights were measured at $\mathrm{d} 9, \mathrm{~d} 15, \mathrm{~d} 21, \mathrm{~d} 28$, and $\mathrm{d} 56$ of the experiment when selected male pups were killed by $\mathrm{CO}_{2}$ inhalation. Sample size varied from 6 to 12 per group on d15-56 because of the variation in number of male pups per dam, which limited sampling on some days. A minimal sample size of 5 rats was estimated by power analysis to detect a 50\% change in PL and PLRP1 mRNA levels with a population variance of $30 \%$ for PL

Table 1. Dietary composition (21)

\begin{tabular}{lccc}
\hline & LF & MF & HF \\
\hline Fat (\% kcal) & 11 & 40 & 67 \\
Carbohydrate (\% kcal) & 67 & 39 & 11 \\
Component [\% Diet & & & \\
$\quad$ (by weight)] & & & \\
Casein & 20 & 20 & 20 \\
DL-methionine & 0.3 & 0.3 & 0.3 \\
AIN-76 mineral mix & 3.5 & 3.5 & 3.5 \\
AIN-76 vitamin mix & 1.0 & 1.0 & 1.0 \\
Choline bitartrate & 0.2 & 0.2 & 0.2 \\
Cellulose & 5.0 & 20.2 & 34.8 \\
Safflower oil & 5.0 & 17.1 & 28.9 \\
Cornstarch & 65.0 & 37.8 & 11.3 \\
\hline
\end{tabular}


and PLRP1. Because of the small pancreatic size on d9, pups were sampled for either PL mRNA or PL activity. Thus, sample size for body weight and pancreatic weight is larger ( $n$ $=20$ ) than for either PL mRNA or PL activity. For d15 and later, pancreatic size was large enough that a portion of each pancreas was frozen immediately on dry ice and stored at $-80^{\circ} \mathrm{C}$ for enzyme analysis. The remainder of the pancreas was used immediately for RNA isolation as described below.

Fatty acid analysis. To $50 \mathrm{~L}$ of pooled milk samples for each treatment, $30 \mathrm{~g}$ of $\mathrm{C}: 17$ FFA, $500 \mathrm{~L}$ of benzene, and $3 \mathrm{~L}$ of acetylchloride:MeOH (1:15) were added (27). (Because of the small volumes of milk, pooling samples was necessary for sufficient volume for analysis.) The samples were incubated in a $65^{\circ} \mathrm{C}$ water bath for $2 \mathrm{~h}$. After cooling, $10 \mathrm{~g}$ of C: 15 fatty acid methyl ester, internal standard, $500 \mu \mathrm{L}$ of hexane and $1 \mathrm{~L}$ of $\mathrm{H}_{2} \mathrm{O}$ were added, and the samples were centrifuged to separate. The hexane layer was taken and injected into the gas chromatograph for fatty acid analysis (27).

Pancreatic enzyme analysis. Pancreatic fragments were homogenized in 9 vol of PBS $\left(0.15 \mathrm{M}\right.$ of NaCl, $5 \mathrm{mM}$ of $\mathrm{PO}_{4}, \mathrm{pH}$ 7.4) with a Polytron homogenizer. Homogenates were centrifuged at $14,000 \times g$ at $4^{\circ} \mathrm{C}$ for $30 \mathrm{~min}$. The supernatant was removed, and soybean trypsin inhibitor was added (final concentration, $0.01 \%$ ). The supernatant was used for determination of enzyme activity and protein content. Lipase activity was assayed by a titrimeric method (21) with $20 \mathrm{mM}$ of $\mathrm{NaOH}$ using a gum arabic-stabilized emulsion of neutralized triolein with excess crude colipase. Protein was determined by the method of Lowry et al. (28), using bovine albumin as a standard. Enzyme activities were expressed as nits (micromoles of fatty acid released per minute) per milligram of protein.

RNA extraction and hybridization studies. RNA was isolated as described by Chomczynski and Sacchi (29). This method is a single extraction with an acid guanidinium thiocyanate-phenol-chloroform mixture. Freshly isolated pancreatic fragments were immediately homogenized with a Polytron homogenizer (titanium probe) twice for $20 \mathrm{~s}$, in ice-cold $4 \mathrm{M}$ of guanidinium thiocyanate, $26 \mathrm{mM}$ of sodium citrate, $(\mathrm{pH} 7)$, $0.5 \%$ sarcosyl, and $0.7 \%$ 2-mercaptoethanol. Sequentially, the RNA was extracted by adding $0.2 \mathrm{M}$ of sodium acetate $(\mathrm{pH} 4)$ and phenol and chloroform-isoamyl alcohol mixture (49:1). RNA was precipitated with isopropanol, reprecipitated with $75 \%$ ethanol, and dissolved in sterile DEPC-treated water. RNA was quantified by UV absorption at $260 \mathrm{~nm}$. The integrity of RNA was checked by $0.8 \%$ agarose gel electrophoresis for the presence of intact $18 \mathrm{~S}$ and $28 \mathrm{~S}$ ribosomes. Levels of PL, PLRP1, and PLRP2 mRNA and S28 RNA were quantified by dot-blot analysis. Each cDNA used yields a single band on Northern blots as reported by us and others (30,31). Dot blots are more quantitative than Northern blots and were used for this reason. Furthermore, area densitometry is highly correlated with direct Luminescence Scintillation Center (LSC) counting of blots (30). Recombinant plasmids used in these studies were the gifts of Dr. H.F. Kern [University of Marburg, Germany (PLRP1 cDNA; 0.82-kb insert in PstI site of pUC9, (32))], Dr. J. Williams [University of Michigan (PL cDNA; 1.5-kb insert in EcoRI site of pUC18, (30)] and D. Soprano [Temple Uni- versity, Philadelphia (28S cDNA probe), and Dr. P. Howells (PLRP2 cDNA; 1.3-Kb insert in XdaI and KpNI site in pKSII, (33)). Previously, we reported negligible cross-hybridization of PL and PLRP1 (33). We also examined the specificity of the homologous and heterologous hybridization of random primelabeled PL, PLRP1, and PLRP2 cDNA inserts with $0.2 \mu \mathrm{g}$ of linearized plasmid DNA containing PLRP2 insert. Hybridization and washing conditions were identical to those described here. The PLRP2 cDNA cross-hybridization to the PL and PLRP1 plasmid averaged 0 and $0.1 \%$, respectively, of its hybridization to the homologous PLRP2 plasmid. These results demonstrate the specificity of the hybridization of each PL probe under the highly stringent conditions used in this study. Specific mRNAs were quantified by dot-blot hybridization within the range of linear hybridization (30). Total RNA was diluted in DEPC-treated water to the appropriate concentration, verified by absorbance at $260 \mathrm{~nm}$. For denaturation, the samples were mixed with $6.15 \mathrm{M}$ of formaldehyde in $0.75 \mathrm{M}$ of $\mathrm{NaCl}$ and $0.075 \mathrm{M}$ of trisodium citrate $[5 \times \mathrm{SSC} ; 1 \times \mathrm{SSC}$ in $0.15 \mathrm{M}$ of $\mathrm{NaCl}$ and $0.015 \mathrm{M}$ of sodium citrate $(\mathrm{pH} 7)]$ and heated for $15 \mathrm{~min}$ at $65^{\circ} \mathrm{C}$. The denatured samples were spotted onto a nitrocellulose filter using a Millipore dot-blot apparatus. The filters were cross-linked by UV radiation with optimal dosage $\left(120 \mathrm{~mJ} / \mathrm{cm}^{2}\right)$ and prehybridized at $42^{\circ} \mathrm{C}$ for $2 \mathrm{~h}$ in a solution that contained $50 \%$ formamide $5 \times \mathrm{SSC}, 5 \times$ Denhardt's solution, $0.1 \%$ SDS, and $0.03 \%$ tRNA. Hybridization was performed at $42^{\circ} \mathrm{C}$ for $16-18 \mathrm{~h}$ after adding the ${ }^{32} \mathrm{P}$ labeled cDNA probe. Plasmids that contained cDNA inserts were labeled by nick translation for $28 \mathrm{~S}$ and by random priming for PL, PLRP1, and PLRP2 (Promega labeling kits Prime-a-Gene and Nick translation). After hybridization, filters were washed under increasingly stringent conditions $(1 \times \mathrm{SSC}$ with $1 \% \mathrm{SDS}$ to $0.2 \mathrm{M}$ of sodium citrate with $1 \% \mathrm{SDS})$. The films were autoradiographed overnight at $-80^{\circ} \mathrm{C}$. Autoradiographic films were quantified by an area laser densitometer (Bio-Rad) and volume integration. The data were expressed as relative absorbency units of each sample relative to the absorbency of $28 \mathrm{~S}$.

Data analysis. All data, expressed as mean $\pm \mathrm{SE}$, were analyzed by two-way ANOVA (34) for the independent effects of 1) diet, 2) development, and 3) the interaction effects of diet $\times$ development. Data for $\mathrm{d} 9$ were not included in the two-way ANOVA because only the LF group was sampled at this time. The mean for $\mathrm{d} 9 \mathrm{LF}$ is presented for comparison. Results were considered significantly different if $P<0.05$.

\section{RESULTS}

Fatty acid composition of milk. The milk fatty acid composition on 115 of lactation from rats that consumed LF (11\%), MF (40\%), and HF (67\%) safflower oil diets is presented in Table 2. The amount of dietary safflower oil altered the milk fatty acid content with 15- to 100-fold C10:00 and 2.6- to 3.3-fold C18:2 in the milk of lactating rats that consumed MF and HF safflower oil diets, respectively, compared with lactating rats that consumed LF safflower oil diet. This change resulted in an increase in both long-chain/medium-chain ratio 
Table 2. Fatty acid composition of milk from lactating rats that consumed LF (11\%), MF (40\%), or HF (67\%) safflower oil diets on day 15

\begin{tabular}{cccc}
\hline & \multicolumn{3}{c}{ Diet } \\
\cline { 2 - 4 } Fatty acid & LF & MF & HF \\
\hline $10: 0$ & $24.7 \%$ & $0.24 \%$ & $1.6 \%$ \\
$12: 0$ & $0.73 \%$ & $5.5 \%$ & $0.78 \%$ \\
$14: 0$ & $0.55 \%$ & $4.5 \%$ & $0.59 \%$ \\
$14: 1$ & $0.05 \%$ & $0.0007 \%$ & Not detected \\
$15: 0$ & $0.43 \%$ & $0.003 \%$ & $0.25 \%$ \\
$15: 1$ & $0.07 \%$ & Not detected & Not detected \\
$16: 0$ & $28.7 \%$ & $11.7 \%$ & $6.2 \%$ \\
$16: 1$ & $2.19 \%$ & $0.3 \%$ & $0.07 \%$ \\
$17: 0$ & $3.4 \%$ & $0.16 \%$ & $2.3 \%$ \\
$17: 1$ & $0.06 \%$ & $0.17 \%$ & Not detected \\
$18: 0$ & $3.2 \%$ & $2.8 \%$ & $3 \%$ \\
$18: 1$ & $13.5 \%$ & $12.3 \%$ & $11.7 \%$ \\
$18: 2$ & $22 \%$ & $58.9 \%$ & $71.9 \%$ \\
$18: 3$ & $0.13 \%$ & $3.1 \%$ & $1.3 \%$ \\
$20: 0$ & $0.07 \%$ & $4.1 \%$ & $0.29 \%$ \\
P/S ratio & 2.8 & 8.6 & 72.5 \\
Long/medium-chain ratio & 0.38 & 2.9 & 5.6 \\
\hline
\end{tabular}

from 2.8 for $\mathrm{LF}$ to 72.5 for $\mathrm{HF}$ and the polyunsaturated/ saturated ratio $(\mathrm{P} / \mathrm{S})$ from 0.38 for $\mathrm{LF}$ to 5.6 for $\mathrm{HF}$.

Final body weight. There was significant independent effect of diet $(\mathrm{LF}=\mathrm{MF}>\mathrm{HF} ; P<0.001)$ with a small $(12$ and $13.5 \%$ ) decrease in the final body weight in weanling or adult rats fed HF safflower diets. There was also a significant effect of development $(15 \mathrm{~d}<21 \mathrm{~d}<28 \mathrm{~d}<56 \mathrm{~d} ; P<0.001)$ with increasing body weight from d15 through $\mathrm{d} 56$ (Fig. 1).

Food consumption. The average food consumption per day was measured in 28- and 56-d-old rats after they were weaned.

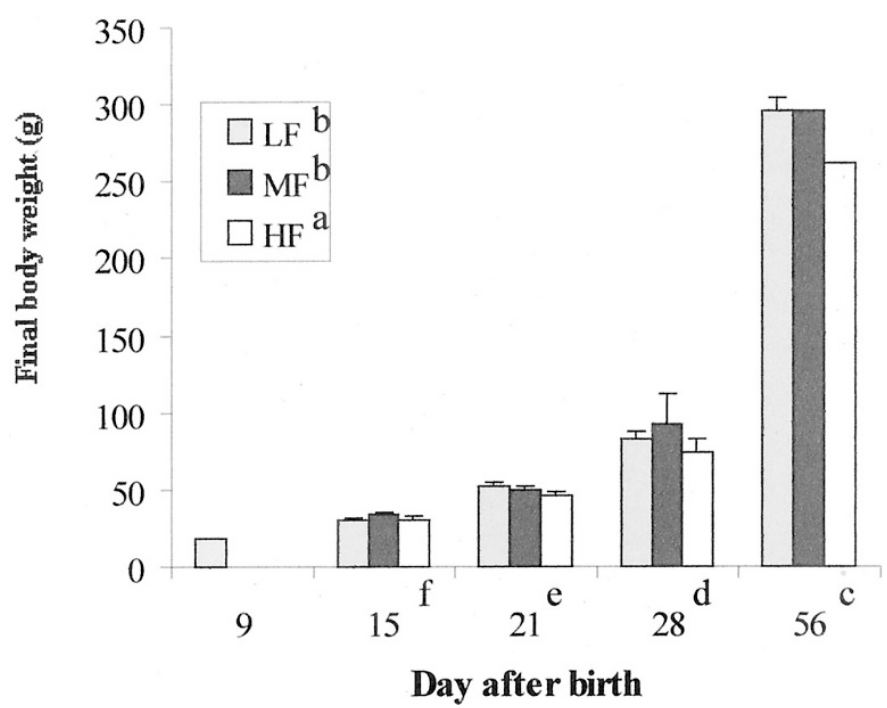

Figure 1. Final body weight of rats that consumed LF (11\% as energy; $\square$ ), MF (40\% as energy; $\square$ ), and HF (67\% as energy; $\square$ ) safflower oil diets. Results are expressed as mean \pm SE. Any bars without visible SE had SE less than the smallest unit on the graph. There was independent effect of diet (LF $=\mathrm{MF}>\mathrm{HF} ; P<0.001 ;{ }^{\mathrm{a}, \mathrm{b}}$ diet not sharing a superscript differed significantly) and of development (d15 $<\mathrm{d} 21<\mathrm{d} 28<\mathrm{d} 56 ; P<0.001$; $^{\mathrm{c}-\mathrm{f}}$ days not sharing a superscript differed significantly). There was no significant interaction of diet $\times$ development. The number of male pups per sample were $9 \mathrm{~d}$ (20 per group), $15 \mathrm{~d}$ (9-10 per group), $21 \mathrm{~d}$ ( $7-11$ per group), $28 \mathrm{~d}$ (6-9 per group), and $56 \mathrm{~d}$ (8-12 per group).
Table 3. Food consumption of rats that consumed $L F, M F$, or $H F$ safflower oil diets

\begin{tabular}{lrrr}
\hline & \multicolumn{3}{c}{ Food intake $(\mathrm{g} / \mathrm{d})$} \\
\cline { 2 - 4 } Day from birth & \multicolumn{1}{c}{$\mathrm{LF}^{*}$} & \multicolumn{1}{c}{ MF $\dagger$} & \multicolumn{1}{c}{ HF $\ddagger$} \\
\hline $28^{*}$ & $9.6 \pm 1.0$ & $9.0 \pm 0.4$ & $7.0 \pm 1.0$ \\
$56 \dagger$ & $21.0 \pm 0.6$ & $19.0 \pm 1.5$ & $17.0 \pm 1.4$ \\
\hline Data are mean \pm SE. \\
There was an independent effect of diet $(\mathrm{LF}<\mathrm{MF}<\mathrm{HF} ; P<0.001)$. Diets \\
not sharing a symbol were significantly different. \\
There was an independent effect of days (d28 $<\mathrm{d} 56 ; P<0.001)$. Days not \\
sharing a symbol were significantly different.
\end{tabular}

There was a significant independent effect of diet $(\mathrm{LF}<\mathrm{MF}<$ HF; $P<0.001)$ and of development $(28 \mathrm{~d}<56 \mathrm{~d}$; $P<0.001)$. The food consumption was significantly lower in 28 - and 56-d-old rats that consumed the HF diet compared with rats that consumed the LF and MF diets (Table 3).

Pancreatic lipase activity. There was a significant independent effect of diet $(\mathrm{LF}<\mathrm{MF}=\mathrm{HF} ; P<0.002)$ and of development $(15 \mathrm{~d}<21 \mathrm{~d}<28 \mathrm{~d}=56 \mathrm{~d}$; $P<0.001$; Fig. 2$)$ on pancreatic lipase activity expressed as $\mathrm{U} / \mathrm{mg}$ pancreas. There was also a significant interaction of diet $\times$ development $(P<$ $0.001)$. In 15-d-old pups before weaning, PL activity was greater in pups that consumed LF and MF diets (55 and 65\%, respectively) compared with pups that consumed the HF diet, although lipase activity was extremely low (6- to 20-fold less than d28). By d21, PL activity increased 6-fold and was greater in HF-fed rats (83 and $75 \%$, respectively; $P<0.05$ ) than in LF- or MF-fed rats. At $28 \mathrm{~d}$, PL activity was 3 -fold greater in HF- and MF-fed rats than in LF-fed rats $(P<0.05)$. A similar effect of diet was seen at $56 \mathrm{~d}$ with 2-fold greater PL activity in HF-fed rats compared with LF-fed rats and intermediate levels in MF-fed rats. As shown in Table 4, similar changes in PL activity are seen when PL activity is expressed as total units per pancreas.

PL mRNA levels. There were significant independent effects of diet ( $\mathrm{LF}<\mathrm{MF}=\mathrm{HF} ; P<0.013)$ and of development $(28 \mathrm{~d}$ $>56 \mathrm{~d}>21 \mathrm{~d}>15 \mathrm{~d} ; P<0.001)$ but no interaction of diet $\times$ development on PL mRNA levels (Fig. 3). PL mRNA levels were very low at 9 and $15 \mathrm{~d}$ but increased significantly by $\mathrm{d} 21$ through adulthood (2- to 4-fold, respectively). By d21, lipase mRNA levels increased 2- to 3-fold and were greater in the MF- and HF-fed rats. The maximal effect of diet was seen at d28.

PLRP1 mRNA levels. There was a significant independent effect of development $(15 \mathrm{~d}=21 \mathrm{~d}>28 \mathrm{~d}>56 \mathrm{~d} ; P<0.001)$. There was no independent affect of diet. The PLRP1 mRNA levels were very high during 9 and $15 \mathrm{~d}$ but decreased significantly by $28 \mathrm{~d}$ through adulthood (2- to 4 -fold, respectively; Fig. 4).

PLRP2 mRNA levels. We report for the first time a significant independent effect of diet on the regulation of PLRP2 ( $P$ $<0.004$; Fig. 5). PLRP2 mRNA levels decreased in HF-fed pups (79 and 90.3\%, respectively) compared with LF- and MF-fed pups on d15. There was a significant effect of development (15d $>21 \mathrm{~d} ; P<0.001)$. There was also a significant interaction of diet $\times$ development $(P<0.002)$. PLRP2 mRNA 


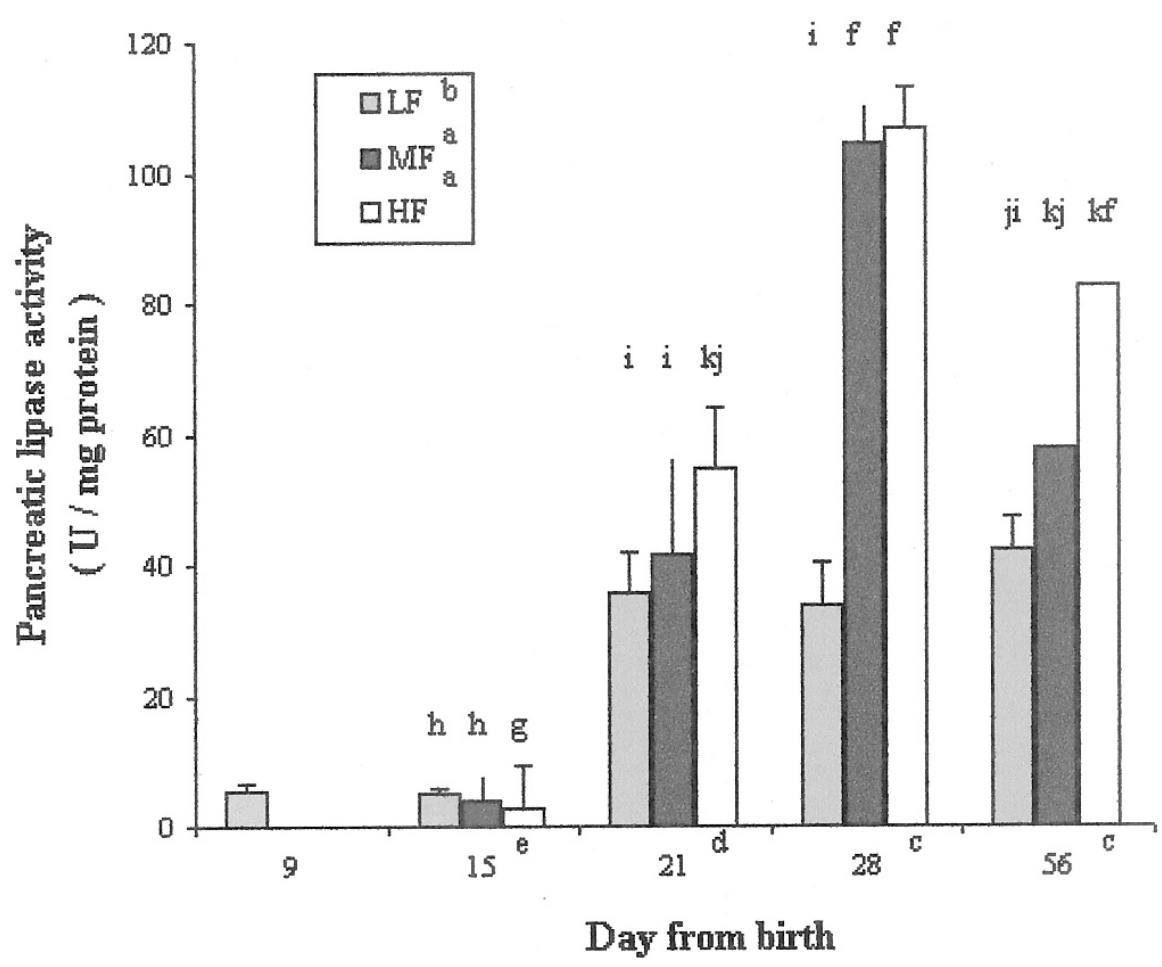

Figure 2. Pancreatic lipase activity (U/mg of protein) of rats that consumed LF (11\% as energy; $\square$ ), MF ( $40 \%$ as energy; $\square$ ), and HF (67\% as energy; $\square$ ) safflower oil diets. Results are expressed as mean \pm SE. Any bars without visible SE had SE less than the smallest unit on the graph. There was independent effect of diet (LF $<$ MF $=$ HF; $P<0.002 ;{ }^{\text {a,b }}$ diet not sharing a superscript differed significantly) and of development $(\mathrm{d} 15<\mathrm{d} 21<\mathrm{d} 28=\mathrm{d} 56 ; P<0.001$; ${ }^{\mathrm{c}-\mathrm{e}}$ days not sharing a superscript differed significantly). There was significant interaction of diet $\times$ development $\left(P<0.001\right.$; ${ }^{\mathrm{f}-\mathrm{k}}$ values not sharing a superscript differed significantly). The number of male pups per sample were $9 \mathrm{~d}$ ( 9 per group), $15 \mathrm{~d}$ (7-10 per group), $21 \mathrm{~d}$ ( $7-10$ per group), $28 \mathrm{~d}$ (6-9 per group), and $56 \mathrm{~d}(6-12$ per group).

Table 4. Total pancreatic lipase of rats that consumed LF $(11 \%$ of energy), MF (40\% of energy), or HF (67\% of energy) safflower oil diets

\begin{tabular}{|c|c|c|c|}
\hline \multirow[b]{2}{*}{ Day } & \multicolumn{3}{|c|}{ Total pancreatic lipase (U/pancreas) } \\
\hline & $\mathrm{LF} \dagger$ & MF* & $\mathrm{HF}^{*}$ \\
\hline 9 & $13.3 \pm 1.6$ & - & - \\
\hline $15^{*}$ & $10.3 \pm 2.0^{*}$ & $7.0 \pm 1.4^{*}$ & $5.9 \pm 1.6^{*}$ \\
\hline $21 \dagger$ & $201.3 \pm 26.8 \dagger$ & $539.3 \pm 101.5 \dagger \$$ & $547.2 \pm 85.4 \dagger t$ \\
\hline $28 \$$ & $457.2 \pm 66.0 \dagger \S \dagger$ & $878.5 \pm 206.0 \S \Phi !$ & $980.4 \pm 256.8 \S \rrbracket+$ \\
\hline $56 \S$ & $1801.0 \pm 271.8 \mathbf{q} \|$ & $2491.8 \pm 367.2 \|$ & $3649.0 \pm 512.4 \|$ \\
\hline
\end{tabular}

Data are mean $\pm \mathrm{SE}$.

There was a significant independent effect of diet $(\mathrm{LF}<\mathrm{MF}=\mathrm{HF} ; P<$ 0.02 ). Diets not sharing a symbol were significantly different.

There was a significantly independent effect of development $(P<0.001$; $\mathrm{d} 15<\mathrm{d} 21<\mathrm{d} 28<\mathrm{d} 56)$. Days not sharing a symbol differed significantly.

There was significant interaction of diet $\times$ development $(P<0.014)$. Values not sharing a symbol differed significantly.

levels decreased from $\mathrm{d} 9$ to $\mathrm{d} 28$ when the PLRP2 mRNA levels were undetectable.

\section{DISCUSSION}

PL, PLRP1, and PLRP2 are of the same genetic family, as demonstrated by their gene homology and structural similarity $(8,35,36)$. Both PLRP1 and PLRP2 gene expression have a different developmental pattern than PL mRNA (9). This anticoordinate regulation of PLRPs and PL suggests that during rat development, the genes for the PLRPs are under different regulatory controls than the PL gene. The relative high levels

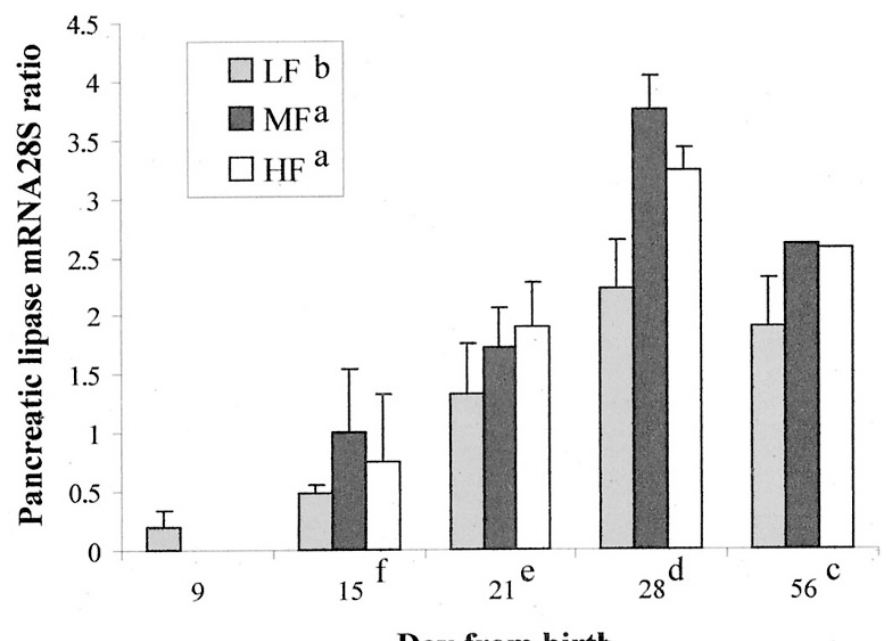

Day from birth

Figure 3. Pancreatic lipase mRNA/S28 ratio of rats that consumed LF $(11 \%$ as energy; $\square$ ), MF ( $40 \%$ as energy; $\square$ ), and HF (67\% as energy; $\square$ ) safflower oil diets. Results are expressed as mean $\pm \mathrm{SE}$. Any bars without visible SE had SE less than the smallest unit on the graph. There was independent effect of diet $\left(\mathrm{LF}<\mathrm{HF}=\mathrm{MF} ; P<0.013 ;{ }^{\mathrm{a}, \mathrm{b}}\right.$ diet not sharing a superscript differed significantly) and of development $(\mathrm{d} 15<\mathrm{d} 21<\mathrm{d} 56<\mathrm{d} 28 ; P<0.001$; ${ }^{\mathrm{c}-\mathrm{f}}$ days not sharing a superscript differed significantly). The number of male pups per sample were $9 \mathrm{~d}$ (12 per group), $15 \mathrm{~d}$ (7-10 per group), $21 \mathrm{~d}$ ( 6 per group), $28 \mathrm{~d}$ (6-9 per group), and $56 \mathrm{~d}$ ( $8-12$ per group).

of PLRP mRNA around birth suggest that they may play an important role in the suckling and suckling-nibbling phase, when the rat is consuming maternal milk and maternal diet. 


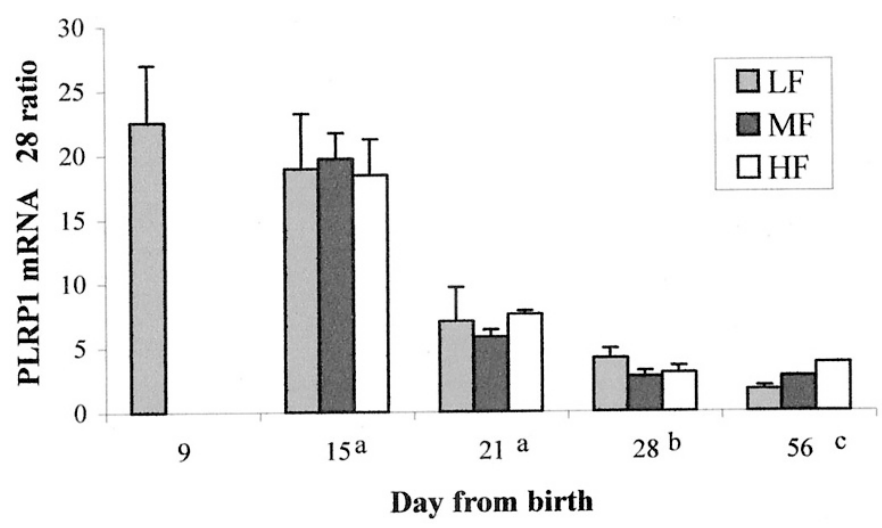

Figure 4. PLRP $1 \mathrm{mRNA} / \mathrm{S} 28$ ratio of rats that consumed LF (11\% as energy; $\square$ ), MF ( $40 \%$ as energy; $\square$ ), and HF (67\% as energy; $\square$ ) safflower oil diets. Results are expressed as mean \pm SE. Any bars without visible SE had SE less than the smallest unit on the graph. There was independent effect of development (d56 $<\mathrm{d} 28<\mathrm{d} 21<\mathrm{d} 15 ; P<0.001 ;{ }^{\mathrm{a}-\mathrm{c}}$ days not sharing a superscript differed significantly). There was no significant effect of diet and interaction of diet $\times$ development. The number of male pups per sample were $9 \mathrm{~d}(15$ per group), $15 \mathrm{~d}$ ( $7-10$ per group), $21 \mathrm{~d}$ ( 6 per group), $28 \mathrm{~d}$ ( $6-8$ per group), and $56 \mathrm{~d}$ (6-11 per group).

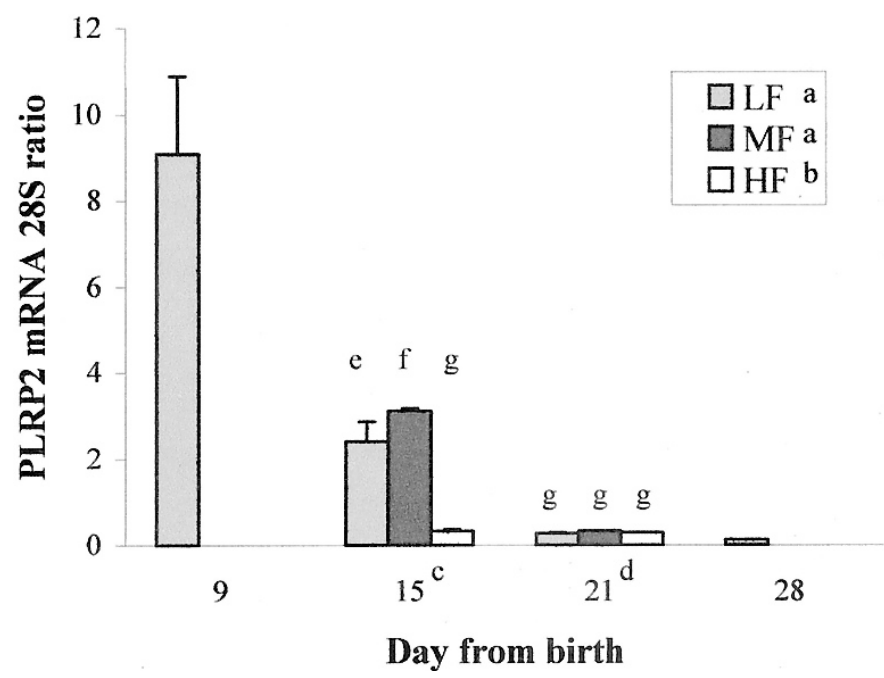

Figure 5. PLRP 2 mRNA/S28 ratio of rats that consumed LF ( $11 \%$ as energy; $\square$ ), MF ( $40 \%$ as energy; $\square$ ), and HF (67\% as energy; $\square$ ) safflower oil diets. Results are expressed as mean \pm SE. Any bars without visible SE had SE less than the smallest unit on the graph. There was independent effect of diet (LF $=\mathrm{MF}>\mathrm{HF} ; P<0.004 ;{ }^{\mathrm{a}, \mathrm{b}}$ diet not sharing a superscript differed significantly) and of development (d21 $<\mathrm{d} 15 ; P<0.001 ;{ }^{\mathrm{c}-\mathrm{d}}$ days not sharing a superscript differed significantly). There was significant interaction of diet $\times$ development $\left(P<0.002 ;{ }^{\mathrm{e}-\mathrm{g}}\right.$ values not sharing a superscript differed significantly). The number of male pups per sample were $9 \mathrm{~d}$ (10 per group), $15 \mathrm{~d}$ (8-10 per group), and $21 \mathrm{~d}$ (9 per group).

Altering the maternal dietary fat content did alter the milk fatty acid content in dams that consumed low, moderate, and high levels of safflower oil. The amount of PUFA (mainly 18:2) in milk was elevated as maternal dietary polyunsaturated fat increased. This phenomenon is in agreement with previous studies (23-25).

This significant change in the milk fatty acid composition consumed by the pups allowed us to determine whether PL and its related proteins are regulated by dietary fat in the suckling phase and the suckling-nibbling phase, when the pups consume both maternal milk and purified diet. Increased polyunsaturated fat, independent of developmental stage, significantly increased PL activity and mRNA in a parallel manner as described previously $(\mathrm{MF}=\mathrm{HF}>\mathrm{LF})$. However, there was also a complex interactive effect between diet and developmental stage. At the suckling-nibbling phase (d15), high polyunsaturated fat in suckled milk or nibbled maternal diet decreased PL activity in pups without changing its mRNA levels. This suggests that this early dietary regulation of PL activity in the suckling-nibbling phase may be due to translational or posttranslational regulation. This is also the first report of dietary regulation of PL in the preweaned rat, as previous studies on adaptation of PL to dietary fat all have been in weaned or adult animals. The parallel changes found in PL mRNA levels and activity in the weanling and adult rat in this study are concordant with previous studies $(20,22,37)$ and suggest that the dietary regulation of PL postweaning is pretranslational or transcriptional. PL exhibited the previously reported (9) developmental regulation, independent of diet; PL activity and mRNA levels were low at $\mathrm{d} 9$ and $\mathrm{d} 15$ and increased to maximal levels by $\mathrm{d} 28$.

PLRP1 mRNA levels were significantly affected by development in agreement with previous reports by Payne et al. (9). PLRP1 mRNA levels were high during the early postnatal period (d9 and d15) and declined sharply after weaning (d21) to low levels in adulthood. The different amount of polyunsaturated fat in the milk and the diet did not affect expression of PLRP1. The lack of influence of amount of fat in diet on PLRP1 expression in weanling rats in this work is surprising and differs from other studies $(16,20,22,37)$, in which PLRP1 was shown to be transcriptionally regulated by dietary fat. However, the introduction of different amounts of PUFA, started earlier during the tertiary phase of pancreatic development, may alter the long-term regulation of PLRP1. Such "metabolic imprinting" has been proposed for other dietary lipids such as cholesterol but remains highly controversial.

The developmental expression of PLRP2 mRNA was high during the early postnatal period and declined sharply until the weaning phase ( $21 \mathrm{~d}$ postnatally) to undetectable levels in adulthood (d56). This agrees with the developmental pattern reported initially by Payne et al. (9). As early as, $15 \mathrm{~d}$ during the suckling-nibbling phase, there was a significant effect of $\operatorname{diet}(\mathrm{LF}=\mathrm{MF}>\mathrm{HF} ; P<0.004)$ on PLRP2 mRNA levels. Pups that consumed milk with high levels of PUFA had significantly reduced PLRP2 mRNA levels compared with pups that consumed milk with low or moderate levels of PUFA. This is the first report of regulation of PLRP2 by different amounts of polyunsaturated fat introduced early during development. Given the report by Lowe et al. (5) that suckling PLRP2-deficient mice exhibit fat malabsorption and the suppression of PLRP2 by high levels of long-chain polyunsaturated fat in the early postnatal period, found in our study, it is clear that PLRP2 has an important role in digestion of fat at the early postnatal period.

In conclusion, three pancreatic lipases (PL, PLRP1, and PLRP2) are differentially regulated by diet. PL and PLRP2 are regulated anticoordinately at the suckling stage by dietary PUFA. This dietary regulation of these two enzymes at a very 
early stage of development may have significance in the digestion of fat in the newborn. Diets with high levels of polyunsaturated fat and low levels of saturated fat suppress PLRP2. Whether this has an adverse impact on fat digestion and absorption needs to be determined in future studies. When considering the appropriate balance of PUFA and other fats for optimal fat digestion in early neonates, the developmental and dietary regulation of the different lipases, including PL and PLRP2, should taken into consideration.

\section{REFERENCES}

1. Lien EL 1994 The role of fatty acids composition and positional distribution in fat absorption in infants. J Pediatr 125:S62-S68

2. Giovannini M, Agostoni C, Salari PC 1991 The role of lipids in nutrition during the first months of life. J Int Med Res 19:351-362

3. Hamosh M, Bitman J, Liao TH, Mehta NR, Buczek RJ, Wood DL, Grylack LJ, Hamosh P 1989 Gastric lipolysis and fat absorption in preterm infants: effect of medium chain triglyceride or long chain triglyceride-containing formulas. Pediatrics $83: 86-92$

4. Carriere F, Barrowman JA, Verger R, Laugier R 1993 Secretion and contribution to lipolysis of gastric and pancreatic lipase during a test meal in humans. Gastroenterology 105:876-888

5. Lowe ME, Kaplan MH, Jackson-Grusby L, D’Agostino D, Grusby MJ 1998 Decreased neonatal dietary fat absorption and $\mathrm{T}$ cell cytotoxicity in pancreatic lipaserelated protein 2-deficient mice. J Biol Chem 273:31215-31221

6. Bernback S, Blackberg L, Hernell O 1990 The complete digestion of human milk triacylglycerol in vitro requires gastric lipase, pancreatic colipase- dependent lipase, and bile salt-stimulated lipase. J Clin Invest 85:1221-1226

7. Bernback S, Blackberg L, Hernell O 1989 Fatty acids generated by gastric lipase promote human milk triacylglycerol digestion by pancreatic colipase-dependent lipase. Biochim Biophys Acta 1001:286-293

8. Giller T, Buchwald P, Blum-Kaelin D, Hunziker W 1992 Two novel human pancreatic lipase related proteins, hPLRP1 and hPLRP2. Differences in colipase dependence and in lipase activity. J Biol Chem 267:16509-16516

9. Payne RM, Sims MF, Jennens ML, Lowe ME 1994 Rat pancreatic lipase and two related proteins: enzymatic properties and mRNA expression during development. Am J Physiol 266:G914-G921

10. de Caro J, Carriere F, Barboni P, Giller T, Verger R, de Caro A 1998 Pancreatic lipase-related protein (PLRP1) is present in the pancreatic juice of several species. Biochim Biophys Acta 1387:331-341

11. Bezzine S, Roussel A, de Caro J, Gastinel L, de Caro A, Carriere F, Leydier S, Verger $\mathrm{R}$, Cambillau C 1998 An inactive pancreatic-related protein is activated into a triglyceride-lipase by mutagenesis based on the 3-D structure. Chem Phys Lipids 93:103-114

12. Crenon I, Jayne S, Kerfelec B, Hermoso J, Pignol D, Chapus C 1998 Pancreatic lipase-related protein type 1: a double mutation restores a significant lipase activity. Biochem Biophys Res Commun 246:513-517

13. Roussel A, de Caro J, Bezzine S, Gastinel L, de Caro A, Carriere F, Leydier S, Verger $\mathrm{R}$, Cambillau C 1998 Reactivation of the totally inactive pancreatic lipase RP1 by structure-predicted point mutations. Proteins 32:523-531
14. Andersson L, Carriere F, Lowe ME, Nilisson A, Verger R 1996 Pancreatic lipaserelated protein 2 but not classical pancreatic lipase hydrolyzes galactolipids. Biochim Biophys Acta 1302:236-240

15. Yang Y, Sanchez D, Figarella C, Lowe ME 2000 Discoordinate expression of pancreatic lipase and two related proteins in human fetal pancreas. Pediatr Res 47:184-188

16. Brannon PM 1990 Adaptation of the exocrine pancreas to diet. Ann Rev Nutr 10:85-105

17. Spannagel AW, Nakano I, Tawil T, Chey WY, Liddle RA, Green GM 1996 Adaptation to fat markedly increases pancreatic secretory response to intraduodenal fat in rats. Am J Physiol 270:G128-G135

18. Dagorn JC 1986 Mechanism of pancreas adaptation to diet. Biochimie 68:229-231

19. Gidez LI 1973 Effect of dietary fat on pancreatic lipase levels in the rat. J Lipid Res 14:169-177

20. Ricketts J, Brannon PM 1994 Amount and type of dietary fat regulate pancreatic lipase gene expression in rats. J Nutr 124:1166-1117

21. Sabb JE, Godfrey PM, Brannon PM 1986 Adaptive response of rat pancreatic lipase to dietary fat: effects of amount and type of fat. J Nutr 116:892-899

22. Wicker C, Puigserver A 1989 Changes in mRNA levels of rat pancreatic lipase in the early days of consumption of a high lipid diet. Eur J Biochem 180:563-567

23. Grigor MR, Warren SM 1980 Dietary regulation of mammary lipogenesis in lactating rats. Biochem J 188:61-65

24. Neville MC, Picciano MF 1997 Regulation of milk lipid secretion and composition. Annu Rev Nutr 17:159-183

25. Williamson DH 1980 Integration of metabolism in tissues of the lactating rat. FEBS Lett 117:K93-K105

26. Schneeman BO, Gallaher D 1980 Changes in small intestinal digestive enzyme activity and bile acids with dietary cellulose in rats. J Nutr 110:584-590

27. Lillington JM, Trafford DJ, Makin HI 1981 A rapid and simple method for the esterification of fatty acids and steroid carboxylic acids prior to gas-liquid chromatography. Clin Chim Acta 111:91-98

28. Lowry OH, Roserough NJ, Farr AL, Randall RJ 1951 Protein measurement with the Folin phenol reagent. J Biol Chem 193:265-275

29. Chomczynski P, Sacchi N 1997 Single step method of isolation by acid guanidinium thiocyanate-phenol-chloroform extraction. Anal Biochem 162:156-159

30. Tsai A, Cowan MR, Johnson DG, Brannon PM 1994 Regulation of pancreatic amylase and lipase gene expression by diet and insulin in diabetic rats. Am J Physiol 267:G575-G583

31. Wishart MJ, Andrews PC, Nichols R, Blevis GT, Logsdon CD, Williams JA 1993 Identification and cloning of the GP-3 from rat pancreatic acinar zymogen granules as a glycosylated membrane-associated lipase. J Biol Chem 268:10303-10311

32. Steinhilber W, Poensgen J, Rausch U, Kern HF, Scheele GA 1988 Translationa control of anionic trypsinogen and amylase synthesis in rat pancreas in response to caerulein stimulation. Proc Natl Acad Sci USA 85:6597-6601

33. Tsai A, Cowan MR, Johnson DG, Brannon PM 1994 Regulation of pancreatic amylase and lipase gene expression by diet and insulin in diabetic rats. Am J Physiol 267:G575-G583

34. Steel RGD, Torrie JH 1960 Principles and Procedures of Statistics. McGraw-Hill, New York

35. Grusby MJ, Nabavi N, Wong H, Dick RF, Bluestone JA, Schotz MC, Glimcher LH 1990 Cloning of an interleukin-4 inducible gene from cytotoxic T lymphocytes and its identification as a lipase. Cell 60:451-459

36. Lowe ME, Rosenblum JL, Strauss AW 1989 Cloning and characterization of human pancreatic lipase cDNA. J Biol Chem 264:20042-20048

37. Wicker C, Puigserver A 1990 Expression of rat pancreatic lipase gene is modulated by a lipid-rich diet at a transcriptional level. Biochem Biophys Res Commun $166: 358-364$ 